\title{
NEAR INFRARED LIGHT HEATING OF SOFT TISSUE PHANTOMS CONTAINING NANOPARTICLES
}

\author{
S. Eibner ${ }^{\mathrm{a}}$, \\ R. A. O. Jaime ${ }^{\text {, }}$ \\ B. Lamien', \\ R. L. Q. Bastob, \\ H. R. B. Orlande ${ }^{b}$, \\ ABSTRACT \\ The objective of this paper is to investigate the effect of the addition of \\ nanoparticles to soft tissue phantoms, aiming at the enhancement of \\ photothermal therapy for cancer. The phantoms were made of Polyvinyl \\ chloride-plastisol (PVC-P), with two different nanoparticles, namely, \\ titanium dioxide nanoparticles $\left(\mathrm{TiO}_{2}\right)$ and silica nanoparticles $\left(\mathrm{SiO}_{2}\right)$. A \\ phantom without nanoparticles and a phantom containing a thermal paste \\ were also manufactured for comparison purposes. The PVC-P phantom is \\ transparent to the near infrared laser light, whereas the addition of titanium \\ dioxide nanoparticles modified the optical properties enhancing the local \\ heating, as demonstrated through experiments with a laser-diode and an \\ á́cole des Mines d'Albi-Carmaux \\ Campus Jarlard - 81013 Albi CT Cédex 09 \\ infrared camera. \\ seibner@mines-albi.fr \\ ${ }^{b}$ Universidade Federal do Rio de Janeiro \\ Departamento de Engenharia Mecânica \\ COPPE \\ Cidade Universitária \\ CEP. 68503, Rio de Janeiro, Brasil \\ Received: November 19, 2013 \\ Revised: November 20, 2013 \\ Accepted: December 20, 2013 \\ Keywords: hyperthermia, NIR laser, photothermal therapy, phantom, \\ photoabsorbing nanoparticles.

\section{NOMENCLATURE} \\ a larger ellipses semi-axis, $m$ \\ b smaller ellipses semi-axis, $m$ \\ $\mathrm{B}_{\mathrm{a}} \quad$ bias limit of quantity a \\ $\mathrm{C}_{\mathrm{p}}$ fluid specific heat at constant pressure, \\ $\mathrm{J} /(\mathrm{kg} . \mathrm{K})$ \\ D tube diameter, $\mathrm{m}$ \\ E ellipses eccentricity, b/a \\ $\mathrm{H}$ array height, $\mathrm{m}$ \\ $\mathrm{K}$ fluid thermal conductivity, W/(m.K) \\ $\mathrm{L}$ array length, $\mathrm{m}$ \\ $\frac{\mathrm{L}}{\mathrm{2b}}$ array length to smaller ellipses axis aspect

$$
\text { ratio }
$$ \\ $\mathrm{m} \quad$ total mass of the arrangement, $\mathrm{kg}$ \\ $\tilde{\mathrm{m}}$ dimensionless total mass of the arrangement \\ $\mathrm{n}_{\mathrm{f}} \quad$ number of fins \\ $\mathrm{n}_{\mathrm{t}} \quad$ total number of tubes \\ $\mathrm{N}$ number of tubes in one unit cell \\ $\mathrm{N}_{\mathrm{ec}} \quad$ number of elemental channels \\ p pressure, $\mathrm{N} / \mathrm{m}^{2}$ \\ $\mathrm{P}$ dimensionless pressure \\ $\mathrm{Pe}_{2 b} \quad$ Peclet number based on smaller ellipses axis \\ Pr fluid Prandtl number, $v / \alpha$ \\ $\mathrm{P}_{\mathrm{a}} \quad$ precision limit of quantity a \\ $\tilde{\mathrm{q}}_{*} \quad$ dimensionless overall thermal conductance, \\ Eq.(15) \\ Q overall heat transfer rate, $\mathrm{W}$ \\ $R_{2 b}$ Reynolds number based on smaller ellipses \\ axis, $\mathrm{u}_{\infty} 2 \mathrm{~b} / \mathrm{v}$ \\ $\mathrm{S} \quad$ spacing between rows of tubes, m, Fig. 1 \\ S/D dimensionless spacing between rows of tubes \\ (circular arrangement) \\ $\mathrm{S} / 2 \mathrm{~b}$ dimensionless spacing between rows of tubes \\ (elliptic arrangement) \\ $\mathrm{t}$ time, $\mathrm{s}$ \\ $t_{f} \quad$ fin thickness, $m$ \\ $t_{t} \quad$ tube thickness, $m$ \\ $\mathrm{T} \quad$ average fluid temperature, $\mathrm{K}$ \\ $\mathrm{u}_{1}, \mathrm{u}_{2}, \mathrm{u}_{3}$ velocity components, $\mathrm{m} / \mathrm{s}$ \\ $\mathrm{U}_{1}, \mathrm{U}_{2}, \mathrm{U}_{3}$ dimensionless velocity components \\ $\mathrm{U}_{\mathrm{a}} \quad$ uncertainty of quantity a \\ $\mathrm{W}$ array width, $\mathrm{m}$ \\ $\mathrm{x}, \mathrm{y}, \mathrm{z}$ cartesian coordinates, $\mathrm{m}$ \\ $\mathrm{X}, \mathrm{Y}, \mathrm{Z}$ dimensionless cartesian coordinates

\section{Greek symbols} \\ $\alpha \quad$ thermal diffusivity, $\mathrm{m}^{2} / \mathrm{s}$ \\ $\varepsilon \quad$ mesh convergence criterion, Eq. (21) \\ $\delta \quad$ fin-to-fin spacing, $m$
}


$\theta \quad$ dimensionless temperature

$\bar{\theta}$ dimensionless average fluid temperature

$v \quad$ fluid kinematic viscosity, $\mathrm{m}^{2} / \mathrm{s}$

$\rho$ density, $\mathrm{kg} / \mathrm{m}^{3}$

$\phi_{\mathrm{f}} \quad$ dimensionless fin density in direction $\mathrm{z}$

$\tau$ dimensionless time

\section{Subscripts}

$\begin{array}{ll}\text { in } & \text { unit cell inlet } \\ \mathrm{m} & \text { maximum } \\ \text { opt } & \text { optimal } \\ \text { out } & \text { unit cell outlet } \\ \mathrm{s} & \text { solid tube wall and fin material } \\ \mathrm{w} & \text { tube surface } \\ \infty & \text { free stream }\end{array}$

\section{INTRODUCTION}

In medicine, hyperthermia refers to a moderate use of heat to increase the temperature of human tissues for therapeutic purposes. For example, it has been used for the treatment of cancer in chemotherapy, for rapid drug delivery by increasing blood flow in the cancerous region, or in radiotherapy, by making cancerous cells more sensitive to radiation (Chekuri et al., 2010). Besides that, tumorous cells are more sensitive to heat than normal cells. Consequently, protocols based solely on hyperthermia have been used for irreversible damage to tumorous cells, which is caused by the rupture of the cell membrane and denaturing of proteins. Such effects take place in temperatures ranging from $41{ }^{\circ} \mathrm{C}$ to $47^{\circ} \mathrm{C}$. Heating strategies such as laser, microwave, radiofrequency and ultrasound waves have been used to heat a specific target region for cancer treatment. Common drawbacks related to these methods are the undesirable burning of healthy cells and the difficulty to achieve uniform temperatures in the tumor volume (Huang et al., 2008). On the other hand, extracorporeal laser heating of a specific target region containing photothermal agents is not invasive and very selective, in order to achieve hyperthermia (Feng et al., 2009; Dickerson et al., 2008). Such a method, in which photoabsorbing agents are used as light/heat converters, has received the name photothermal therapy (PTT). Primary investigations in this field dealt with the use of natural chromophores, or externally added dye molecules, as photothermal agents. Natural chromophores, however suffer from very low absorption, while small dye molecules suffer from photobleaching under laser irradiation (Huang et al., 2008).

Recent advances in nanotechnology allowed the production of nanoparticles with enhanced optical properties for a localized surface plasmon resonance. This is a resonant phenomenon in which light induces oscillations of conductive electrons at the surface of metal nanoparticles (Hirsch et al., 2003). Interestingly, such a local phenomenon depends on the wavelength of the incident light through the geometrical properties of the nanoparticles. Therefore, proper design may induce it to occur in the near-infrared (NIR) region of the spectrum. Indeed, this is the optical window within which light penetration depth in tissue is optimal, due to minimal light absorption of water and hemoglobin. Noble metal nanoparticles, as compared to photothermal agents which have been used in the past, do not suffer from photobleaching and enable considerable laser power reduction due to their strong cross section absorption (Huang et al., 2008). Lastly, a number of in vitro and in vivo investigations reported by different research groups demonstrate the practical use of nanoparticles made from noble metals, such as, gold and silver, or single-walled carbon nanotubes as hyperthermic agents in photothermal therapy (Hirsch et al., 2003; O’Neal et al., 2004; Huff et al., 2007; Xu et al., 2011; DasGupta et al., 2009).

Commonly in biomedical investigations, new technologies are evaluated on phantoms, prior to experiments with animals or human tissues. Phantoms are liquid or solid materials designed in a way that their properties simulate those of human tissues. Materials, such as intralipid ( $\mathrm{Xu}, 2003$ ), polyacrylamide gel (Tanaka, 1981), agar gel (Korte, 1981) and polyvinyl chloride-plastisol (Spirou et al., 2005) have been used for the preparation of phantoms of soft-tissues.

In this work, an experimental analysis of PVC-P (polyvinyl chloride plastisol) phantoms containing nanoparticles and subjected to NIR laser irradiation is performed. Phantoms were prepared containing nanoparticles of titanium dioxide $\left(\mathrm{TiO}_{2}\right)$ or silica $\left(\mathrm{SiO}_{2}\right)$. A phantom without nanoparticles and a phantom containing a thermal paste were also manufactured for comparison purposes. The phantoms were characterized in terms of their optical and thermal properties, and experiments were conducted where the temperature variations of phantoms heated with a NIR laser were measured with an infrared camera.

\section{MATERIALS AND METHODS}

For the preparation of the phantoms in this work, we made use of PVC-P (polyvinyl chloride plastisol, M-F Manufacturing Co., Fort Worth, TX, USA). PVC-P is a non-toxic plastic, commonly used for making fishing lures. PVC-P does not absorb light in the near infrared region (600 to $1200 \mathrm{~nm}$ ), which makes it attractive to simulate human tissues for the application under analysis. It is a white opaque solution of monomers that polymerizes and becomes translucent (in the visible spectrum), when heated to high temperatures (Spirou et al., 2005). PVC-P phantoms can be easily prepared by heating the PVC$\mathrm{P}$ liquid solution to approximately $200^{\circ} \mathrm{C}$ and continuously stirring the solution with a magnetic stirrer, for about 2 hours. Afterwards, the solution is 
let to cool down in a mold (with a cylindrical shape in this work). The diameter of the mold is $25.4 \mathrm{~mm}$ and its thickness approximately $3 \mathrm{~mm}$.

The preparation of the phantoms embedded with nanoparticles basically followed the same procedure used to produce regular PVC-P phantoms, but the PVC-P solution was mixed with a nanofluid before being heated. Two different commercial nanofluids were used in this work, both provided by US Research Nanomaterials, Inc. One of the nanofluids consisted of an aqueous solution of $\mathrm{TiO}_{2}$ nanoparticles, with mean diameters of $15 \mathrm{~nm}$, and concentration of $15 \mathrm{wt} \%$. The other nanofluid used in this work also consisted of an aqueous solution, but of silica nanoparticles $\left(\mathrm{SiO}_{2}\right)$, with mean diameters of $30 \mathrm{~nm}$, and concentration of $25 \mathrm{wt} \%$. The mixture of the nanofluid and PVC-P was heated to $200^{\circ} \mathrm{C}$, under continuous stirring with a magnetic stirrer, for about 2 hours. Afterwards, it was cool down in the cylindrical shaped mold.

For comparison purposes, a phantom consisting of mixture of thermal paste and PVC-P was also manufactured, by following basically the same procedure described above. The thermal paste was manufactured by Implastec (Thermal Silver). The thermal paste was mixed with PVC-P, before heating. Table 1 summarizes the characteristics of the phantoms manufactured, which are presented in Fig. 1.

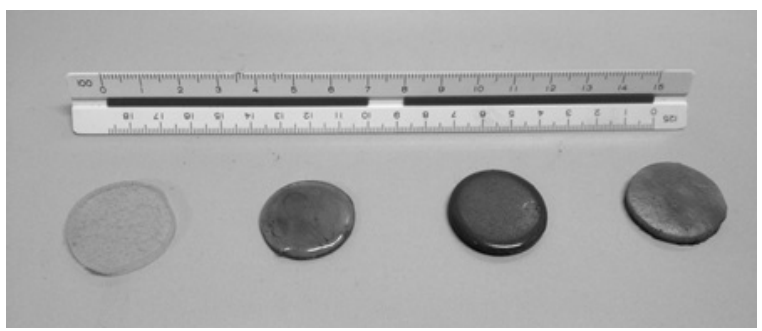

Figure 1. From left to right, phantoms made of: PVC$\mathrm{P}$, PVC-P and $\mathrm{SiO}_{2}$ nanoparticles, PVC-P and thermal paste, $\mathrm{PVC}-\mathrm{P}$ and $\mathrm{TiO}_{2}$ nanoparticles.

Table 1. Phantoms' characteristics.

\begin{tabular}{|c|c|c|}
\hline Phantom & $\begin{array}{c}\text { Thickness } \\
(\mathrm{mm})\end{array}$ & $\begin{array}{c}\text { Concentration } \\
(\%)\end{array}$ \\
\hline PVC-P & 2.70 & - \\
\hline $\begin{array}{c}\text { PVC-P with } \\
\mathrm{SiO}_{2} \\
\text { nanoparticles }\end{array}$ & 3.2 & 3.05 \\
\hline $\begin{array}{c}\text { PVC-P with } \\
\text { TiO }\end{array}$ & 2.55 & 0.69 \\
nanoparticles & & 10.56 \\
\hline $\begin{array}{c}\text { PVC-P with } \\
\text { thermal paste }\end{array}$ & 2.80 & \\
\hline
\end{tabular}

\section{Measurement of Optical and Thermal Properties}

The absorption coefficients, at wavelengths ranging from 500 to $900 \mathrm{~nm}$ and 1300 to $2300 \mathrm{~nm}$, were measured with the spectrophotometers Varian CARY100 and Varian 3100 FT-IR, available at IMA (Macromolecules Institute, UFRJ). The thermal diffusivities, densities and specific heats of the produced phantoms were respectively measured with the NETZSCH LFA 447 NanoFlash, with a Sartorius YDK 01 densimeter mounted on a Marte AM 220 scale and with a Differential Scanning Calorimeter NETZSCH - DSC 204 F1 Phoenix.

\section{Experimental Setup}

We used in the experimental setup a nearinfrared diode laser from oclaro, Inc. World Headquarters, supplying light at a mean wavelength of $829.1 \mathrm{~nm}$. The diode laser is connected to a collimator F-H10-NIR-FC from Newport Corporation, by an optical fiber. The laser output power is controlled by a laser diode driver, model 525B from Newport Corporation, allowing a maximum output power of $600 \mathrm{~mW}$. The laser diode was cooled to avoid excessive heating.

In order to avoid transmitted light reflection from the phantom's support, the opaque sample support was selected with very low reflectivity.

In the experiments, the laser diode was set to deliver an output power of $350 \mathrm{~mW}$ on continuous wave mode through the collimator. The laser diode, located $20 \mathrm{~mm}$ above the sample, was perpendicularly pointed to the phantom for irradiation. The phantom was exposed to the laser during $180 \mathrm{~s}$ in all experiments. During irradiation, an IR thermographic camera (FLIR, Thermacam SC660), placed at a distance of $40 \mathrm{~mm}$ above the phantom, was used to measure phantom surface temperature. Also, a thermocouple type $\mathrm{K}$ placed at the interface of the rear face of the phantom and the sample support was used to measure local temperature variation. The thermocouple was connected to an AGILENT 34970 A data acquisition system controlled by a computer. The experimental setup is illustrated in Fig. 2.

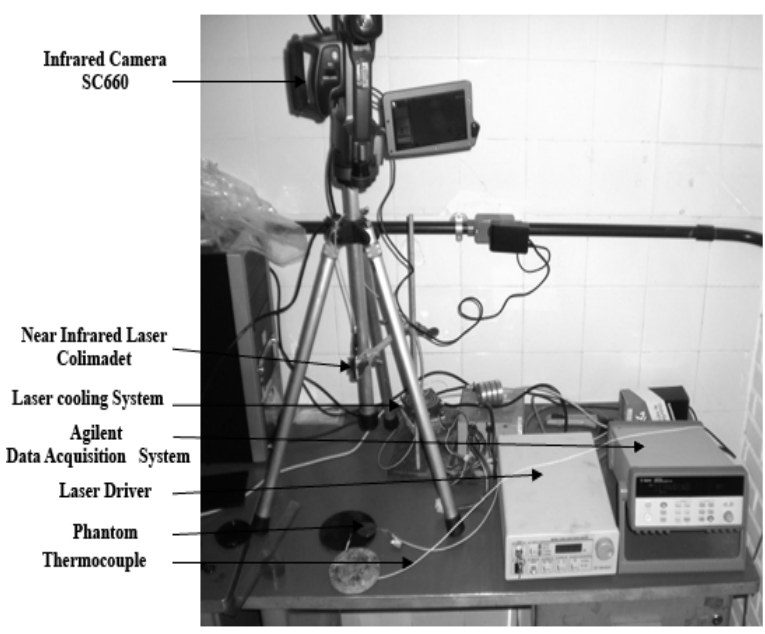

Figure 2. Experimental Setup. 


\section{RESULTS AND DISCUSSION}

Optical characterization of the PVC-P phantom was concerned with the measurement of the absorption coefficient at wavelengths ranging from 500 to $900 \mathrm{~nm}$, using Varian CARY100 Conc. UVvisible and Varian 3100 FT-IR spectrophotometers available at IMA (Macromolecules Institute, UFRJ), respectively.

Figure 3 shows the absorption coefficients of the manufactured phantoms in the range from $800 \mathrm{~nm}$ to $900 \mathrm{~nm}$. The PVC-P absorption coefficient is relatively close to the absorption coefficient of fat at these wavelengths (Kim et al., 2008; Siddiqi, 2009). Figure 3 shows that, in the range of $800 \mathrm{~nm}$ and 900 nm, the use of $\mathrm{SiO}_{2}$ nanoparticles has not significantly affected the absorption coefficient of PVC-P. On the other hand, the absorption coefficient of the phantom containing $\mathrm{TiO}_{2}$ nanoparticles is around six times larger than that of the pure PVC-P phantom. The absorption coefficient of the phantom containing thermal paste is also shown in this figure, only for wavelengths larger than $800 \mathrm{~nm}$, due to large uncertainties at smaller wavelengths. The absorption coefficient of the thermal paste phantom is larger than that of the phantom with $\mathrm{TiO}_{2}$ nanoparticles, but rapidly drops in the range considered for the measurements.

The thermal diffusivities, densities and specific heats of the phantoms were respectively measured with the LFA 447 NanoFlash, with a Sartorius YDK 01 densimeter mounted on a Marte AM 220 scale, and with a Differential Scanning Calorimeter NETZSCH - DSC 204 F1 Phoenix. The obtained results are presented in Tab. 2, while published values of human soft tissues are shown in Tab. 3 (Da Silva et al., 2011). From Tab. 2, it can be seen that the addition of nanoparticles or thermal paste has modified the thermal properties of the pure PVC-P. The density, thermal conductivity and thermal diffusivity of the phantom with thermal paste are larger than those of the phantom made of pure PVC-P and of the phantoms loaded with nanoparticles. The density, thermal conductivity and thermal diffusivity of the phantom with $\mathrm{TiO}_{2}$ nanoparticles are larger than those of the phantom with $\mathrm{SiO}_{2}$ nanoparticles and of the phantom without nanoparticles. Indeed, the addition of $\mathrm{SiO}_{2}$ nanoparticles did not modify the thermal conductivity of the phantom made of pure PVC-P. The largest measured specific heat was for the phantom made of pure PVC-P. Densities of the phantoms with $\mathrm{TiO}_{2}$ nanoparticles and with thermal paste are around those of fat and skin, while the thermal conductivities of all the produced phantoms are around those of fat and of skin.

Transient temperature variations at the center of the non-heated surface of each manufactured phantoms are presented in Fig. 4. Such temperatures were measured with a thermocouple placed at the interface of the sample and its support. As it can be seen in this figure, a temperature variation around 20 ${ }^{\circ} \mathrm{C}$ was achieved for the phantom containing the thermal paste.

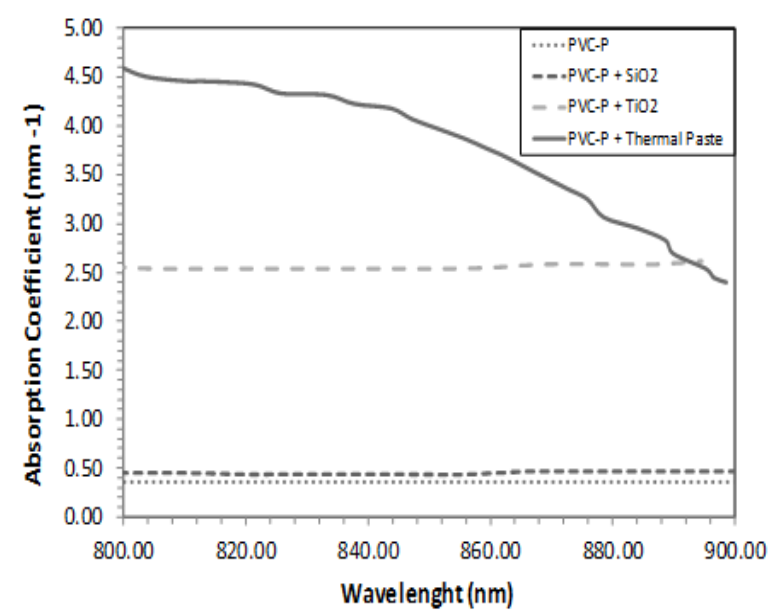

Figure 3. Absorption coefficient of the manufactured phantoms.

Table 2. Thermophysical properties of the prepared phantoms .

\begin{tabular}{|c|c|c|c|c|}
\hline Phantoms & $\begin{array}{c}\text { Density } \\
\left(\mathrm{Kg} / \mathrm{m}^{3}\right)\end{array}$ & $\begin{array}{c}\text { Thermal } \\
\text { diffusivity } \\
\left(10^{-8}\right)\left(\mathrm{m}^{2} / \mathrm{s}\right)\end{array}$ & $\begin{array}{c}\text { Thermal } \\
\text { conductivity } \\
\left(\mathrm{W} / \mathrm{m}^{\circ} \mathrm{C}\right)\end{array}$ & $\begin{array}{c}\text { Specific } \\
\text { Heat } \\
\left(\mathrm{J} / \mathrm{g}^{\circ} \mathrm{C}\right)\end{array}$ \\
\hline $\mathrm{PVC}-\mathrm{P}$ & $995.1 \pm 0.1$ & $8.70 \pm 0.32$ & $\begin{array}{c}0.150 \\
\pm 0.004\end{array}$ & $\begin{array}{c}1.7900 \\
\pm 0.0094\end{array}$ \\
\hline $\begin{array}{c}\mathrm{PVC}-\mathrm{P}+ \\
\mathrm{SiO}_{2}\end{array}$ & $989.3 \pm 0.1$ & $8.76 \pm 0.24$ & $\begin{array}{c}0.150 \\
\pm 0.002\end{array}$ & $\begin{array}{c}1.7200 \\
\pm 0.0097\end{array}$ \\
\hline $\begin{array}{c}\mathrm{PVC}_{2} \mathrm{P}+ \\
\mathrm{TiO}_{2}\end{array}$ & $1,080.8 \pm 0.1$ & $8.80 \pm 0.33$ & $0.173 \pm 0.001$ & $\begin{array}{c}1.7700 \\
\pm 0.0097\end{array}$ \\
\hline $\begin{array}{c}\mathrm{PVC}-\mathrm{P}+ \\
\text { Thermal } \\
\text { Paste }\end{array}$ & $1,094.2 \pm 0.1$ & $12.00 \pm 0.51$ & $0.24 \pm 0.01$ & $\begin{array}{c}1.7500 \\
\pm 0.0049\end{array}$ \\
\hline
\end{tabular}

Table 3. Thermophysical properties of some human soft tissues.

\begin{tabular}{|c|c|c|c|}
\hline Tissues & $\begin{array}{c}\text { Density } \\
(\rho) \\
\left(\mathrm{Kg} / \mathrm{m}^{3}\right)\end{array}$ & $\begin{array}{c}\text { Thermal } \\
\text { condutivity } \\
(k) \\
\left(\mathrm{W} / \mathrm{m}^{\circ} \mathrm{C}\right)\end{array}$ & $\begin{array}{c}\text { Specific Heat } \\
\left(c_{p}\right) \\
\left(\mathrm{J} / \mathrm{Kg}^{\circ} \mathrm{C}\right)\end{array}$ \\
\hline Fat & 1,200 & 0.203 & 2,678 \\
\hline Muscle & 1,097 & 0.529 & 3,684 \\
\hline Skin & 1,200 & 0.228 & 3,593 \\
\hline Bone & 1,585 & 0.735 & 1,785 \\
\hline
\end{tabular}

For the phantom containing $\mathrm{TiO}_{2}$ nanoparticles, a temperature variation of approximately $2.5{ }^{\circ} \mathrm{C}$ was observed. On the other hand, no temperature increase was observed with the phantoms made of pure PVC$\mathrm{P}$ and PVC-P loaded with $\mathrm{SiO}_{2}$ nanoparticles. This is due to the fact that these phantoms are practically transparent to the NIR light used, as demonstrated by Fig. 3, and the slight temperature increase measured by the thermocouple is due to heat diffusion from the sample support to the phantom. As opposed to the $\mathrm{SiO}_{2}$ nanoparticles, the $\mathrm{TiO}_{2}$ nanoparticles have 
enhanced the absorption coefficient of PVC-P (see Fig. 3), so the NIR light was absorbed and heat was generated inside the phantom.

Figure 5 presents a snapshot of the temperature distribution taken by the infrared camera at the final time of the experiment with the phantom containing $\mathrm{TiO}_{2}$ nanoparticles. Figure 6 shows the temperature profile along a cross section line at the top surface of the phantom containing $\mathrm{TiO}_{2}$ nanoparticles, for different times. It can be noticed in this figure that the maximum temperature reached at each time is confined in a region slightly larger than the laser spot. However, in the outer region of the laser spot, heat is diffused and the temperature decreases to reach the initial values at the edge of the phantom.

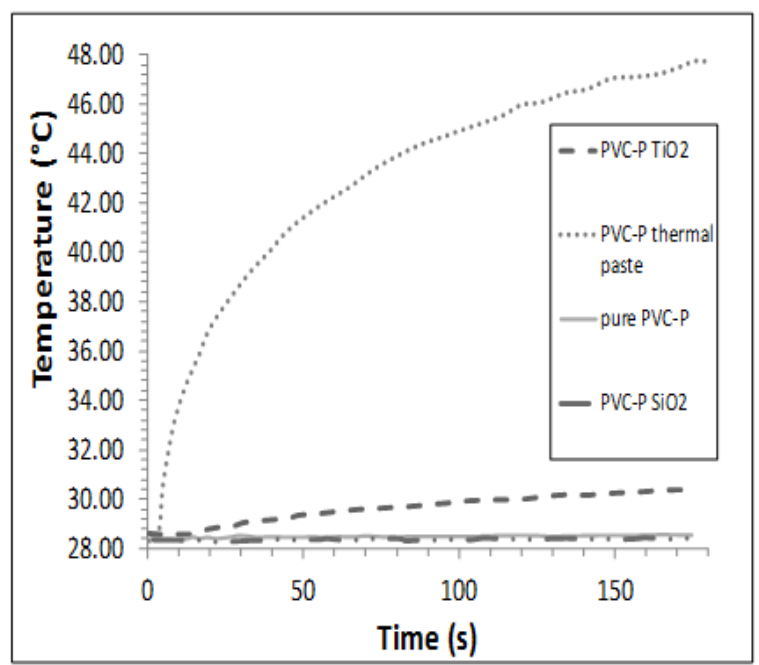

Figure 4. Temperature variation at the non-heated surface of the phantom.

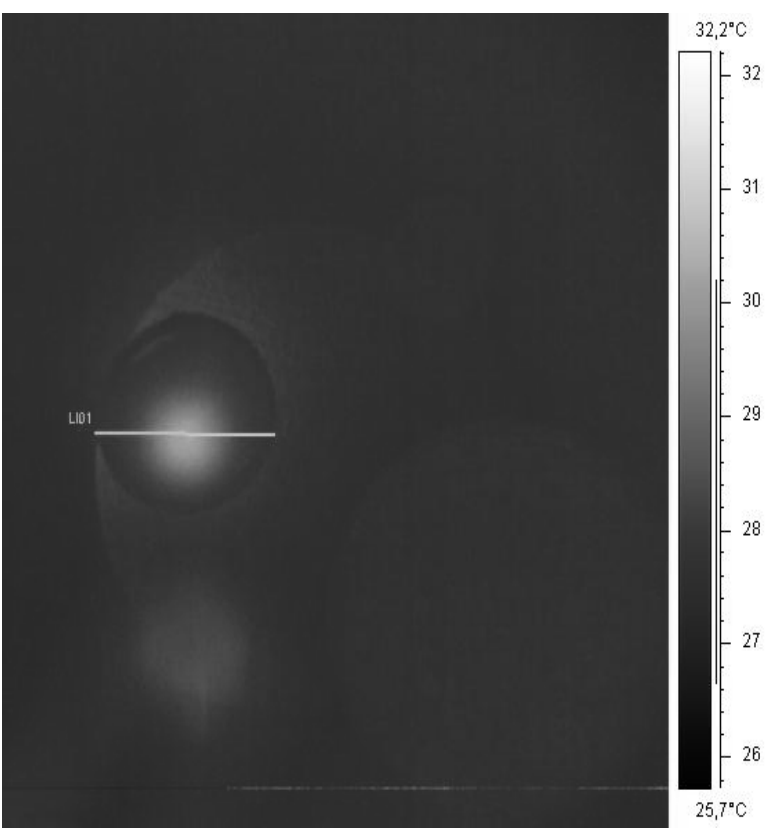

Figure 5. Snapshot of the temperature distribution in the phantom containing $\mathrm{TiO}_{2}$ at $\mathrm{t}=180 \mathrm{~s}$.

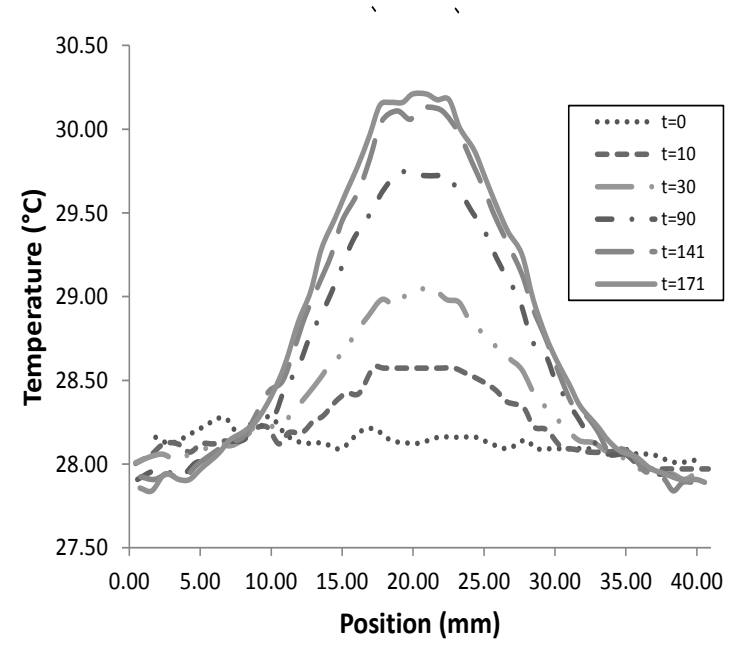

Figure 6. Temperature distribution along a straight line at the front face.

\section{CONCLUSIONS}

This paper presents some preliminary experimental results regarding the NIR light absorption by phantoms loaded with nanoparticles, aiming at the treatment of cancer by hyperthermia. Phantoms were prepared of pure PVC-P, and also of PVC-P with $\mathrm{SiO}_{2}$ nanoparticles and with $\mathrm{TiO}_{2}$ nanoparticles. In addition, a phantom with a thermal paste was prepared for comparison purposes.

It was observed that the pure PVC-P phantom has an absorption coefficient relatively close to that of human fat. The use of $\mathrm{SiO}_{2}$ nanoparticles has not significantly affected the absorption coefficient of PVC-P. On the other hand, the absorption coefficient of the phantom containing $\mathrm{TiO}_{2}$ nanoparticles was around six times larger than that of the pure PVC-P phantom. Densities of the phantoms with $\mathrm{TiO}_{2}$ nanoparticles and with thermal paste are around those of fat and skin, while the thermal conductivities of all the produced phantoms are around those of fat and of skin.

Laser irradiation of the pure PVC-P phantom and of the phantom containing $\mathrm{SiO}_{2}$ nanoparticles has caused no significant variations of their temperatures, as a result of their small absorption coefficients to the NIR light used. As opposed to $\mathrm{SiO}_{2}$ nanoparticles, the use of $\mathrm{TiO}_{2}$ nanoparticles has enhanced significantly the absorption coefficient of pure PVC$\mathrm{P}$, causing the heating of the phantom by the incident laser light. Also, as expected, the largest temperature increase was observed with the phantom containing the thermal paste, because of its high absorption coefficient.

Although the results obtained in this work with the phantom containing $\mathrm{TiO}_{2}$ nanoparticles are promising, further studies are required involving experimental parameters like the laser output power, the laser exposure time, the concentration and spatial 
distribution of the nanoparticles and, very specially, the toxicity of nanoparticles to human beings.

\section{ACKNOWLEDGEMENTS}

The authors are thankful for the support provided by CNPq, CAPES and FAPERJ, Brazilian agencies for the fostering of science. Specific heats of the phantoms were measured by $\mathrm{Mr}$. Maycon Magalhães, at LTTC/COPPE/UFRJ.

\section{REFERENCES}

Chekuri, P., Glazer, E. S., and Curley, S. A, 2010, Targeted Hyperthermia Using Metal Nanoparticles, Advanced Drug Delivery Reviews, Vol. 62, pp. 339-345.

de Korte, C. L., Cespedes, E. I., Van der Steen, A. F., Norder, B., and te Nijenhuis, K., 1997, Elastic and Acoustic Properties of Vessel Mimicking Material for Elasticity Imaging, Ultrason Imaging, Vol. 19, pp. 112-26.

Da Silva, S., França, A. S., and Pinatti, M., 2011, Simulação Unidimensional da Transferência de Calor na Articulação do Joelho Canino durante os Processos de Aquecimento e de Resfriamento Terapêuticos, Revista Brasileira de Engenharia Biomédica, Vol. 27, No. 3, pp. 163-174. (in Portuguese)

DasGupta D., von Maltzahn G., Ghosh S., Bhatia S. N., Das S. K., and Chakraborty S., 2009, Probing Nano Antenna-Directed Photothermal Destruction of Tumors using Non-Invasive Laser Irradiation, Applied Physics Letters, Vol. 95, 233701.

Dickerson, E. B., Dreaden, E. C., Huang, X., ElSayed, I. H., Chu, H., Pushpanketh, S., McDonald, J. F., and El-Sayed, M. A., 2008, Gold Nanorod Assisted Near-Infrared Plasmonic Photothermal Therapy (PPTT) of Squamous Cell Carcinoma in Mice, Cancer Letters, Vol. 269, No. 1, pp. 57-66.

Feng, Y., Fuentes, D., Hawkins, A., Bass, J., Rylander, M. N., Elliott, A., Shetty, A., Stafford, R. J., and Oden, J. T., 2009, Nanoshell-Mediated Laser Surgery Simulation for Prostate Cancer Treatment, Engineering with Computers, Vol. 25, No. 1, pp. 313.

Hirsch, L. R., Stafford, R. J., Bankson, J. A., Sershen, S. R., Price, R. E., Hazle, J. D., Halas, N. J., and West, J. L., 2003, Nanoshell-Mediated NearInfrared Thermal Therapy of Tumors Under MR Guidance, Proceedings of the National Academy of Sciences, Vol. 100, No. 23, pp. 13549-13554.

Huang, X., Jain, P. K., El-Sayed, I. H., and ElSayed, M. A., 2008, Plasmonic Photothermal Therapy (PPTT) using Gold Nanoparticles, Lasers in Medical Science, Vol. 23, pp. 217-228.

Huff, T. B., Tong, L., Zhao, Y., Hansen, M. N., Cheng, J. X., and Wei, A., 2007, Hyperthermic Effects of Gold Nanorods on Tumor Cells, Nanomedicine, Vol. 2, No. 1, pp. 125-132.
Kim, C., Garcia-Uribe, A., Khotapolli, S-R., and Wang, L. V., 2008, Optical Phantoms for UltrasoundModulated Optical Tomography, In Proceedings of SPIE, Vol. 6870, pp. 68700M-1-68700M-8.

O’Neal, D. P., Hirsch, L. R., Lee, M. H., Barton, J., Halas, N. J., and West, J. L., 2004, Photothermal Tumor Ablation in Mice Using Near Infrared Absorbing Nanoshells, Cancer Letters, Vol. 209, pp. 171-176.

Siddiqi, A. K., 2009, Development of Tissueequivalent Heat-sensitive gel for the Experimental Verification of Near Infrared (NIR) Laser Mediated Cancer Detection and Therapy, Doctoral Thesis, Georgia Institute of Technology, Atlanta, Georgia.

Spirou, G. M., Oraevsky, A. A., Vitkin, I. A., and Whelan, W. M., 2005, Optical and Acoustic Properties at $1064 \mathrm{~nm}$ of Polyvinyl Chloride-Plastisol for use as a Tissue Phantom in Biomedical Optoacoustics, Physics in Medicine and Biology, Vol. 50, pp. N141-N143.

Xu, T., Zhang, C.,Wang, X., Zhang, L., and Tian, J., 2003, Measurement and analysis of light distribution in Intralipid-10\% at 650nm, Applied Optics, Vol. 42, pp. 5777-84.

Xu, X., Meade, A., and Bayazitoglu, Y., 2011, Numerical Investigation of Nanoparticle-assisted laser-induced Interstitial Thermotherapy toward Tumor and Cancer Treatments, Lasers in Medical Science, Vol. 26, No. 2, pp. 213-222.

Tanaka, T., 1981, Gels, Scientific American, Vol. 244, No. 1, pp. 124-138. 